Michael L. Platt, Asif A. Ghazanfar (eds.)

\title{
Primate Neuroethology
}

Oxford University Press, Oxford 2010

682 pp.; USD 125.00

ISBN 978-0-19-532659-8

Primate Neuroethology is a synthesis of various areas of research on primate behaviour and cognition. Topics discussed are quite heterogeneous in scope, from studying cognitive abilities in wild primates to exploring the neural function of primate behaviour in a controlled laboratory setting.

Increasing intelligence appears to have played a special role in the evolution of primates, and multiple theories have been proposed to explain the enlarged brain sizes and advanced cognitive abilities seen among primates. Primate Neuroethology contains excellent reviews of some of these dominating hypotheses, including social intelligence and knowledge about the spatiotemporal distribution of resources.

Numerous neocortical differences comprise many of the cognitive modifications seen among primates, and so understanding the neural basis of primate behaviour and anatomy provides clues as to the evolutionary pressures acting on the development of these features. There are several intriguing chapters in Primate Neuroethology which map how vocal communication, locomotion, vision and hearing are all encoded within the primate brain. Additionally, one chapter discusses the neurochemical control of primates' behavioural complexity, and several other chapters highlight the neuroethological mechanisms that comprise such distinctive cognitive features as numerical calculation, associative memory, reward learning, decision-making, executive control, object recognition and attention.

Finally, the concept of 'emotion' (and thus arguably 'emotional intelligence') of primates has played an important role in the advancement of animal welfare policies by providing insight into the diversity of ways in which individuals can perceive and experience their surroundings. Primate Neuroethology contains one chapter that discusses the neural processing of emotional states, and identifies key structures used to evaluate emotional stimuli and responses within the primate brain.

The broad coverage of research topics this book has managed to capture is astounding, and the literature reviews are endlessly useful from a practical standpoint. The book would make an excellent addition to the university classroom, or for scholars wishing to expand their general knowledge of the new and exciting discoveries currently being uncovered from this field of primatology.

\begin{tabular}{ll}
\hline KARGER & ( ) 2011 S. Karger AG, Basel \\
0015-5713/10/0816-0360 \$26.00/0 \\
Fax+4161306 12 34 & \\
$\begin{array}{l}\text { E-Mail karger@karger.ch } \\
\text { www.karger.com }\end{array}$ & $\begin{array}{l}\text { Accessible online at: } \\
\text { www.karger.com/fpr }\end{array}$
\end{tabular}


While Primate Neuroethology contributes greatly to our understanding of the cognitive foundations for primate behaviour, I must point out that many of the chapters in this book obtained data using invasive techniques such as fMRI scanning, and, in fact, some chapters even include disturbing photographs of primates with their heads in clamps and electrodes attached to their bodies. Researchers have an ethical responsibility towards ensuring the well-being of the animals they study, and none of these chapters has provided any mention of adherence to animal welfare legislation and policies. We must gauge the cost of such studies against the value of their contribution to the field of primate cognitive research, and I believe this is something the editors should have ensured was clearly acknowledged within the book.

F. Blake Morton, Stirling 